\title{
The Effect of Lifestyle Changes on Blood Pressure Control among Hypertensive Patients
}

\author{
Myung Hwa Yang ${ }^{1}$, Seo Young Kang' ${ }^{1}$ Jung Ah Lee', Young Sik Kim ${ }^{1}$,* Eun Ju Sung², Ka-Young Lee ${ }^{3}$, Jun-Su Kim³ \\ Han Jin $\mathrm{Oh}^{4}$, Hee Chul Kang ${ }^{5}$, Sang Yeoup Lee ${ }^{6}$ \\ 'Department of Family Medicine, Asan Medical Center, University of Ulsan College of Medicine, Seoul, Korea \\ ${ }^{2}$ Department of Family Medicine, Kangbuk Samsung Hospital, Sungkyunkwan University School of Medicine, Seoul, Korea \\ ${ }^{3}$ Department of Family Medicine, Inje University Busan Paik Hospital, Inje University College of Medicine, Busan, Korea \\ ${ }^{4}$ Department of Family Medicine, Vievisnamuh Hospital, Seoul, Korea \\ ${ }^{5}$ Department of Family Medicine, Yonsei University College of Medicine, Seoul, Korea \\ ${ }^{6}$ Department of Family Medicine, Pusan National University Yangsan Hospital, Pusan National University School of Medicine, Yangsan, Korea
}

Background: Hypertension is highly prevalent among patients who visit primary care clinics. Various factors and lifestyle behaviors are associated with effective blood pressure control. We aimed to identify factors and lifestyle modifications associated with blood pressure control among patients prescribed antihypertensive agents.

Methods: This survey was conducted at 15 hospital-based family practices in Korea from July 2008 to June 2010. We prospectively recruited and retrospectively assessed 1,453 patients prescribed candesartan. An initial evaluation of patients' lifestyles was performed using individual questions. Follow-up questionnaires were administered at 4, 8, and 12 weeks. We defined successful blood pressure control as blood pressure $<140 \mathrm{~mm} \mathrm{Hg}$ systolic and $<90 \mathrm{~mm}$ Hg diastolic.

Results: Of the 1,453 patients, 1,139 patients with available data for initial and final blood pressures were included. In the univariate analysis of the change in performance index, weight gain (odds ratio [OR], 2.18; 95\% confidence interval $[\mathrm{CI}], 1.52$ to 3.11; $\mathrm{P}<0.001$ ), physical inactivity (OR, 1.195; 95\% CI, 1.175 to 3.387; $\mathrm{P}=0.011$ ), and increased salt intake (OR, 1.461; 95\% CI, 1.029 to $2.075 ; \mathrm{P}=0.034$ ) were related to inadequate blood pressure control. Salt intake also showed a significant association. Multivariate ORs were calculated for age, sex, body mass index, education, income, alcohol consumption, smoking status, salt intake, comorbidity, and family history of hypertension. In the multivariate analysis, sex (OR, 3.55; 95\% CI, 2.02 to 6.26; $\mathrm{P}<0.001)$, salt intake (OR, 0.64; 95\% CI 0.43 to 0.97 ; $\mathrm{P}=0.034$ ), and comorbidity ( $\mathrm{OR}, 1.82 ; 95 \% \mathrm{CI}, 1.23$ to 2.69 ; $\mathrm{P}=0.003$ ) were associated with successful blood pressure control.

Conclusion: Weight gain, physical inactivity, and high salt intake were associated with inadequate blood pressure control.

Keywords: Hypertension; Lifestyle Change; Physical Activity; Salt Intake 


\section{INTRODUCTION}

Globally, hypertension is one of the leading causes of mortality, one of the principle risk factors for cardiovascular disease, and a major cause of premature death. ${ }^{1)}$ Hypertension is difficult to diagnose until medical complications occur, since patients rarely present with specific symptoms in the early stages of the disease. Hypertension is also difficult to manage effectively, as is consistent treatment after it is diagnosed, due to lack of awareness and patient compliance. ${ }^{2)}$

Hypertension is a major modifiable risk factor for cardiovascular diseases and stroke. Proper treatment of hypertension can reduce the risk of stroke up to $42 \%$ and the risk of coronary heart disease by about $14 \% .{ }^{3)}$ However, various lifestyle factors are associated with cardiovascular disease and hypertension, such as smoking, obesity, diabetes, dyslipidemia, and others. Lifestyle is a vital issue in managing hypertension since optimal therapy of the disease involves consideration of the patient's age, sex, race, diet, exercise, tobacco use, comorbid conditions, use of antihypertensive drug treatment, compliance, and achievement of blood pressure control. ${ }^{4)}$ Bruno et al. ${ }^{5)}$ studied the prevalence of systemic arterial hypertension and its association with modifiable risk factors in young adults. Male sex, adiposity, and alimentary habits were identified as the main determinants of high blood pressure values, and therefore, were identified as factors for healthy lifestyle interventions.

Approximately $20 \%$ of the adult population worldwide has hypertension. In 2013, the prevalence of hypertension included $27.3 \%$ of Korean adults, aged over 30 years. The direct and indirect medical costs of hypertension are huge, considering the number of patients and families that are affected, and the related costs of treatment, including blood pressure-related complications. Effective blood pressure management is multifactorial and requires the commitment of patients, families, healthcare providers, and communities. ${ }^{6)}$ It is important for physicians to recognize patients' health behaviors in order to provide proper advice and consistent follow-up.

There are many studies on factors associated with hypertension. However, prospective studies on the effect of lifestyle modification on blood pressure control are rare, especially in East Asia. One research study investigated the effect of an access-enhanced intervention on hypertension screening and management, as well as on health behaviors among newly diagnosed hypertensives, in a multi-ethnic low socioeconomic status community in Singapore. The results show some positive effects of intervention on the management of hypertension, but lifestyle changes showed a less significant effect. ${ }^{\text {?) }}$

The purpose of this study was to identify factors and to evaluate lifestyle modifications associated with blood pressure control among patients who were prescribed hypertension medication at a primary care clinic.

\section{METHODS}

\section{Study Design and Subjects}

This study was a multi-center, observational study conducted at 15 hospital-based family practices in Korea from July 2008 to June 2010. We prospectively recruited and retrospectively assessed 1,453 patients with hypertension who were prescribed candesartan. An inclusion criterion was available blood pressure data of patients for each clinic visit to assess hypertension control. Participants with missing age or sex were excluded. Also participants who did not measure blood pressure were excluded. A total of 1,139 patients were included in the study. The study was reviewed and approved by the institutional review board of Asan Medical Center (2008-0290).

We prospectively recruited and retrospectively assessed patients with hypertension who were newly prescribed candesartan. Preliminary assessments on patients' lifestyle including smoking, alcohol consumption, salt intake, and physical activity were conducted using individual survey questions. Basic information including income, education, and marital status were also collected.

This study is an additional analysis of a randomized controlled trial of the effect of mobile phone text message reminders on compliance and lifestyle modification in patients with hypertension. ${ }^{8)}$

\section{Follow-Up and Survey Questions}

Patients who agreed to participate in the study were given survey questions for initial inquiry and follow-up inquiries were made at week 4, 8, and 12 in the outpatient clinic. Attending physicians recorded the data from each appointment. This included the date, antihypertensive drug usage, drug adherence rate, two blood pressure measurements with the mean value, weight, change in alcohol consumption, change in physical activity, and change in salt intake.

Participants filled out initial hypertension survey questionnaires at the first medical appointment, and follow-up survey questionnaires at each follow-up visit to the clinic. In the initial survey, basic characteristics including sex, age, monthly income, education, marital status, smoking status, alcohol consumption, physical activity, body mass index (BMI), habit of salt intake, comorbidities (diabetes, dyslipidemia, cardiovascular disease, and stroke), family medical history, and other prescribed medication use were documented.

Smoking status was divided into three groups: 'never smoker,' 'current smoker,' and 'ever smoker.' Alcohol consumption was defined as 'drinker' and 'non-drinker.' If the answer was 'drinker', the follow-up question was "How often per week?" 'Non-drinker' included someone who never drinks or who drinks only once per month.

We used the International Physical Activity Questionnaire-Short Form (IPAQ-SF) for evaluating physical activity. The IPAQ-SF asks about three specific types of activity (walking, moderate intensity activities, and vigorous intensity activities) and hours spent sitting in the past 7 days. Volume of activity was computed by measuring each activity based on its energy requirements, defined as metabolic equivalent tasks (METs) (walking=3.3 METs, moderate physical activity=4.0 
Table 1. Demographic characteristics of the patients who succeeded or failed in BP control

\begin{tabular}{|c|c|c|c|c|}
\hline Characteristic & Total $(n=1,139)$ & Success $(n=961)^{*}$ & Failure $(n=178)$ & P-value \\
\hline Age (y) & & $64.89 \pm 10.22$ & & $<0.001$ \\
\hline$\leq 50$ & $92(8.1)$ & $68(7.1)$ & $24(13.5)$ & \\
\hline $51-60$ & $282(24.8)$ & $220(22.9)$ & $62(34.8)$ & \\
\hline $61-70$ & 425 (37.3) & $372(38.7)$ & $53(29.8)$ & \\
\hline$\geq 71$ & $340(29.9)$ & $301(31.3)$ & $39(21.9)$ & \\
\hline Sex & & & & $<0.001$ \\
\hline Male & $449(39.4)$ & $340(35.4)$ & 109 (61.2) & \\
\hline Female & $690(60.6)$ & $621(64.6)$ & $69(38.8)$ & \\
\hline Body mass index $\left(\mathrm{kg} / \mathrm{m}^{2}\right)$ & & $25.12 \pm 3.03$ & & 0.013 \\
\hline$<23.0$ & $234(20.5)$ & $207(23.0)$ & $27(16.7)$ & \\
\hline $23.0-24.9$ & 311 (27.3) & $272(30.2)$ & $39(24.1)$ & \\
\hline$\geq 25.0$ & $517(45.4)$ & $421(46.8)$ & $96(59.3)$ & \\
\hline Unknown & $77(6.8)$ & - & - & \\
\hline Education (y) & & & & $<0.001$ \\
\hline$<12$ & 301 (26.4) & $270(29.3)$ & $31(17.8)$ & \\
\hline 12 & 435 (38.2) & $376(40.8)$ & $59(33.9)$ & \\
\hline$>12$ & $360(31.6)$ & $276(29.9)$ & $84(48.3)$ & \\
\hline Unknown & $43(3.8)$ & - & - & \\
\hline Income (million won/mo) & & & & 0.042 \\
\hline$>400$ & $469(41.2)$ & $384(43.7)$ & $80(50.6)$ & \\
\hline $200-400$ & $325(28.5)$ & $270(30.7)$ & $55(32.7)$ & \\
\hline$<200$ & $253(22.2)$ & $225(25.6)$ & $28(16.7)$ & \\
\hline Unknown & $92(8.1)$ & - & - & \\
\hline Alcohol consumption & & & & 0.001 \\
\hline None & $722(63.4)$ & $292(31.7)$ & $76(45.0)$ & \\
\hline Drinker & 368 (32.3) & $629(68.3)$ & $93(55.0)$ & \\
\hline Unknown ${ }^{\dagger}$ & $49(4.3)$ & - & - & \\
\hline Smoking & & & & 0.002 \\
\hline Never smoker & $749(65.8)$ & $649(69.9)$ & $100(57.8)$ & \\
\hline Ever smoker & $353(31.0)$ & $280(30.1)$ & $73(42.2)$ & \\
\hline Unknown & $37(3.2)$ & - & - & \\
\hline Degree of physical activity ${ }^{\ddagger}$ & & & & 0.516 \\
\hline Inactive & $328(28.8)$ & $276(43.1)$ & $52(46.8)$ & \\
\hline Minimally active & $199(17.5)$ & $168(26.3)$ & $31(27.9)$ & \\
\hline Health enhancing & $224(19.7)$ & $196(30.6)$ & $28(25.2)$ & \\
\hline Unknown & $388(34.1)$ & - & - & \\
\hline Habit of salt intake ${ }^{\S}$ & & & & $<0.001$ \\
\hline Normal & $797(70.0)$ & $693(74.8)$ & $104(60.1)$ & \\
\hline High & $303(26.6)$ & $234(25.2)$ & 69 (39.9) & \\
\hline Unknown & $39(3.4)$ & - & - & \\
\hline Comorbidity" & & & & 0.003 \\
\hline Present & $644(56.5)$ & $562(59.0)$ & $82(46.9)$ & \\
\hline Absent & $483(42.4)$ & $390(41.0)$ & $93(53.1)$ & \\
\hline Unknown & $12(1.1)$ & - & - & \\
\hline Family history of hypertension & & & & 0.016 \\
\hline Yes & $523(45.9)$ & $427(45.9)$ & $96(55.8)$ & \\
\hline No & $580(50.9)$ & $504(54.1)$ & $76(44.2)$ & \\
\hline Unknown & $36(3.2)$ & - & - & \\
\hline Compliance (\%) & & & & 0.126 \\
\hline$\geq 80$ & $1,059(93.0)$ & $898(95.7)$ & $161(93.1)$ & \\
\hline$<80$ & $52(4.6)$ & $40(4.3)$ & $12(6.9)$ & \\
\hline Unknown & $28(2.5)$ & - & - & \\
\hline No. of medication & & & & 0.893 \\
\hline Atacand only & $696(61.1)$ & $589(61.9)$ & $107(60.5)$ & \\
\hline Atacand +1 & $351(30.8)$ & $295(31.0)$ & $56(31.6)$ & \\
\hline Atacand $+\geq 2$ & $81(7.1)$ & $67(7.0)$ & $14(7.9)$ & \\
\hline Unknown & $11(1.0)$ & - & - & \\
\hline
\end{tabular}

Values are presented as mean \pm standard deviation or number (\%).

BP, blood pressure.

${ }^{*}$ Success in BP control was defined as systolic BP $<140 \mathrm{~mm} \mathrm{Hg}$ and diastolic BP $<90 \mathrm{~mm} \mathrm{Hg}$. †Patients who did not answer the question regarding amount of drinking. *Evaluated using a questionnaire and converted into a metabolic equivalent task score. ${ }^{\circledR}$ High salt intake was defined as total score $>18$ in males and 16 in females based on the questionnaires. "Includes diabetes, hypercholesterolemia, coronary artery disease, and cerebral vascular disease. 
METS, and vigorous physical activity=8.0 METS). MET-minutes is calculated using the following equation: MET-level for each activity $x$ time in minutes $\times$ number of times per week. Minimally active was defined as a minimum of at least $600 \mathrm{MET}-\mathrm{min} / \mathrm{wk}$. Health enhancing activity was defined as a minimum of at least 1,500 MET-min/wk. Others were classified as inactive. ${ }^{9)}$

Habit of salt intake was evaluated by using three questions from the salt usage questionnaire found in the study by Kim et al. ${ }^{10)}$ : "I usually eat salty food," "I add salt or soy sauce on cooked dishes," and "I eat pan-fried or deep-fried food with soy sauce," For all 3 questions, the answers "very salty" or "always" were given a score of 12 and "not salty" and "never" was given a score of 0 . Summation of scores for each question were calculated and 'high salt intake' was defined as a score $>18$ in males and $>16$ in females.

For follow-up clinic visits at week 4, 8, and 12, participants answered questions regarding weight, smoking, alcohol consumption, physical activity, and salt intake.

\section{Measurements}

We defined successful blood pressure control as both less than 140 $\mathrm{mm} \mathrm{Hg}$ systolic and $90 \mathrm{~mm} \mathrm{Hg}$ diastolic at 12 weeks from the initial survey.

For change in performance index, we compared answers from the initial survey questions to the final survey data at 12 weeks. Reduced alcohol use refers to the absolute reduction in the number of drinking episodes and was divided into 4 categories: (1) no change, (2) reduction by $<1$ time per week, (3) reduction by 1-2 times per week, an (4) reduction by $\geq 3$ times per week. Change in BMI was calculated by comparing measurement data at the initial survey and the final survey. An increase in BMI by $>0.5 \mathrm{~kg} / \mathrm{m}^{2}$ or $\leq 0.5 \mathrm{~kg} / \mathrm{m}^{2}$ was also evaluated. For physical activity, changes in MET scores were observed. The salt intake index was calculated from the change in the absolute value of the score based on the questions. We also analyzed salt intake by the change in answers from individual questionnaires and the significance.

\section{Statistical Analysis}

Baseline characteristics of participants and change in performance index, including alcohol use, BMI, physical activity, and salt intake from the initial survey to the final survey at 12 weeks was analyzed using chi-square and independent samples t-test. Multiple logistic regression analysis was done for multivariate analysis. Both univariate and multivariate analysis was done by adjusting the factors that were statistically significant in the demographic characteristics (Table 1). This included age, sex, BMI, education, income, alcohol, smoking, habit of salt intake, comorbidity, and family history of hypertension with a $95 \%$ confidence interval (CI) for the odds ratio (OR).

Statistical analysis was performed using IBM SPSS ver. 21.0 (IBM Corp., Armonk, NY, USA) with significance at the P-value of 0.05 .

\section{RESULTS}

Of the 1,453 patients, 1,139 with available data for initial and follow-up blood pressure measurements at 12 weeks were included. The study population consisted of patients with an average age of 64 years, of whom $60 \%$ were female, and $40 \%$ were male with a mean BMI of $25.1 \pm 3.0 \mathrm{~kg} / \mathrm{m}^{2}$. Among 1,139 participants, 961 (84\%) were in the success group and 178 (16\%) were in the failure group. Comparison of the success and fail groups showed statistical significance in terms of the baseline characteristics of age, sex, BMI, education, income, alcohol use, smoking, salt intake, comorbidity, and family history of hypertension (Table 1).

In the analysis of the OR for factors associated with successful blood pressure control, multivariate ORs were calculated by adjusting age, sex, BMI, education, income, alcohol, smoking, habit of salt intake, comorbidity, and family history. In the analysis, sex (OR, 3.55; 95\% CI, 2.02 to 6.26 ; $\mathrm{P}<0.001$ ), salt intake (OR, $0.64 ; 95 \% \mathrm{CI}, 0.43$ to 0.97 ; $\mathrm{P}=0.034$ ), and comorbidity (OR, 1.82; 95\% $\mathrm{CI}, 1.23$ to 2.69 ; $\mathrm{P}=0.003$ ) were associated with successful blood pressure control (Table 2).

In the univariate analysis of the performance index, increased BMI (OR, 2.18; 95\% CI, 1.52 to $3.11 ; \mathrm{P}<0.001$ ) was related to poor blood pressure control. In addition, a response of "no" for increased physical activity, indicating the same or less physical activity (OR, 1.995; 95\% CI, 1.175 to 3.387; $\mathrm{P}=0.011$ ), and "no" for reduced salt intake (OR, 1.461; 95\% CI, 1.029 to 2.075; $\mathrm{P}=0.034$ ) were also related to less effective blood pressure control compared to patients who responded "yes." Multivariate OR, calculated by adjusting for age, sex, and comorbidity, and increased BMI (OR, 2.01; 95\% CI, 1.39 to 2.91; $\mathrm{P}<0.001$ ), and a response of "no" for increased physical activity (OR, 2.377; 95\% CI, 1.351 to 4.18; $\mathrm{P}=0.003$ ) were statistically significant factors (Table 3 ).

In addition, responses to three questions regarding salt usage behaviors showed a significant association. For question 1, "I usually eat salty food" (self-reported level of salt intake), the OR for a response of "moderate" was significantly increased (OR, 1.83; 95\% CI, 1.25 to 2.67; $\mathrm{P}=0.002$ ). In question 2, "I add salt or soy sauce on cooked dishes" (usage of salt/soy sauce), the answer "never" showed a strong correlation with successful blood pressure control (OR, 3.15; 95\% CI, 1.69 to 5.87; $\mathrm{P}<0.001)$. For question 3, "I eat pan-fried or deep-fried food with soy sauce" (use of soy sauce when eating fried food), the OR for both answers "sometimes" (OR, 1.70; 95\% CI, 1.02 to 2.82; $\mathrm{P}=0.041$ ) and "never" (OR, 2.60; 95\% CI, 1.52 to 4.44 ; $\mathrm{P}<0.001)$ were significantly increased (Table 4).

\section{DISCUSSION}

In this observational study, we found that increased physical activity and reduced salt intake were associated with successful blood pressure control. In addition, increased BMI was negatively associated with adequate blood pressure control. The total rate of successful blood pressure control was $84.4 \%$ ( $64.6 \%$ female and $35.4 \%$ male). Among the baseline characteristics, age, sex, salt intake, and family 
Table 2. Factors associated with successful blood pressure control

\begin{tabular}{|c|c|c|c|c|}
\hline \multirow{2}{*}{ Variable } & \multicolumn{2}{|c|}{ Crude OR } & \multicolumn{2}{|c|}{ Multivariate $\mathrm{OR}^{*}$} \\
\hline & OR $(95 \% \mathrm{Cl})$ & P-value & OR $(95 \% \mathrm{Cl})$ & P-value \\
\hline \multicolumn{5}{|l|}{ Age (y) } \\
\hline$\leq 50$ & 1 (reference) & & 1 (reference) & \\
\hline $51-60$ & $1.252(0.727-2.158)$ & 0.418 & $0.814(0.434-1.526)$ & 0.521 \\
\hline $61-70$ & 2.477 (1.433-4.281) & 0.001 & $1.265(0.648-2.470)$ & 0.492 \\
\hline$\geq 71$ & 2.724 (1.537-4.829) & 0.001 & $1.260(0.614-2.586)$ & 0.592 \\
\hline \multicolumn{5}{|l|}{ Sex } \\
\hline Male & 1 (reference) & & 1 (reference) & \\
\hline Female & $2.885(2.076-4.010)$ & $<0.001$ & 3.554 (2.019-6.257) & $<0.001$ \\
\hline \multicolumn{5}{|l|}{ BMI $\left(\mathrm{kg} / \mathrm{m}^{2}\right)$} \\
\hline$<23.0$ & 1 (reference) & & 1 (reference) & \\
\hline $23.0-24.9$ & $0.910(0.539-1.535)$ & 0.723 & $0.892(0.491-1.623)$ & 0.709 \\
\hline$\geq 25.0$ & $0.572(0.362-0.905)$ & 0.017 & $0.591(0.343-1.017)$ & 0.057 \\
\hline \multicolumn{5}{|l|}{ Education (y) } \\
\hline$<12$ & 1 (reference) & & 1 (reference) & \\
\hline 12 & $0.732(0.461-1.161)$ & 0.185 & $0.827(0.458-1.495)$ & 0.530 \\
\hline$>12$ & $0.377(0.242-0.589)$ & $<0.001$ & $0.702(0.366-1.348)$ & 0.288 \\
\hline \multicolumn{5}{|c|}{ Income (million won/mo) } \\
\hline$>400$ & 1 (reference) & & 1 (reference) & \\
\hline $200-400$ & 1.779 (1.126-2.811) & 0.014 & $1.240(0.676-2.274)$ & 0.488 \\
\hline$<200$ & $1.087(0.748-1.578)$ & 0.663 & $1.354(0.734-2.499)$ & 0.332 \\
\hline \multicolumn{5}{|l|}{ Smoking } \\
\hline Never smoker & 1 (reference) & & 1 (reference) & \\
\hline Ever smoker & $0.591(0.424-0.824)$ & 0.002 & $1.570(0.937-2.629)$ & 0.087 \\
\hline \multicolumn{5}{|c|}{ Degree of physical activity } \\
\hline Inactive & 1 (reference) & & 1 (reference) & \\
\hline Minimally active & $1.111(0.718-1.720)$ & 0.637 & $0.702(0.283-1.744)$ & 0.447 \\
\hline Health enhancing & $1.291(0.846-1.971)$ & 0.236 & $1.234(0.506-3.007)$ & 0.644 \\
\hline \multicolumn{5}{|l|}{ Salt intake } \\
\hline Normal & 1 (reference) & & 1 (reference) & \\
\hline High & $0.509(0.363-0.714)$ & $<0.001$ & $0.644(0.429-0.967)$ & 0.034 \\
\hline \multicolumn{5}{|l|}{ Comorbidity } \\
\hline Absent & 1 (reference) & & 1 (reference) & \\
\hline Present & $1.634(1.182-2.259)$ & 0.003 & $1.818(1.230-2.689)$ & 0.003 \\
\hline \multicolumn{5}{|c|}{ Family history of hypertension } \\
\hline Yes & 1 (reference) & & 1 (reference) & \\
\hline No & 1.491 (1.075-2.068) & 0.017 & $0.799(0.539-1.184)$ & 0.263 \\
\hline \multicolumn{5}{|l|}{ Compliance (\%) } \\
\hline$\geq 80$ & 1 (reference) & & 1 (reference) & \\
\hline$<80$ & $0.598(0.307-1.164)$ & 0.130 & $0.534(0.131-2.167)$ & 0.38 \\
\hline
\end{tabular}

$\mathrm{OR}$, odds ratio; $\mathrm{Cl}$, confidence interval; $\mathrm{BMI}$, body mass index.

*Calculated by adjusting for age, sex, BMl, education, income, alcohol, smoking, habit of salt intake, comorbidity, and family history of hypertension.

history of hypertension showed statistically significant differences between the success group and failure group.

In our study, $75.7 \%$ of males and $90.0 \%$ of females attained their target blood pressure; this is a relatively high achievement rate, compared with that observed in previous studies. This may be due to better compliance and adherence among the women in the survey. This is consistent with the results of another study in Korea that reported higher rates of controlled diabetes and hypertension in women. ${ }^{11)}$ However, in another research study performed in the USA, women, MexicanAmericans, and those aged $\geq 60$ years had significantly lower rates of blood pressure control than men, younger individuals, and non-His- panic whites. ${ }^{12)}$ In addition, patients with comorbidities showed better blood pressure control achievement rates in our study. The higher achievement rate and better adherence compared with patients without comorbidities is similar to the higher adherence trend observed among the women in this study. In a study by Turner et al., ${ }^{13)}$ patients with more unrelated comorbid conditions were less likely to have uncontrolled hypertension at the primary care visit. Also, in another study on hypertension control in relation to concomitant risk factors and comorbidity, the overall degree of control increased with increasing numbers of comorbid diseases. ${ }^{14)}$

The factors associated with the potential antihypertensive effects of 
Table 3. Changes in the performance index between patients with successful and failed blood pressure control

\begin{tabular}{|c|c|c|c|c|c|c|c|}
\hline \multirow{2}{*}{ Variable } & \multirow{2}{*}{ Total } & \multirow{2}{*}{ Failure } & \multirow{2}{*}{ Success } & \multicolumn{2}{|l|}{ Univariate $\mathrm{OR}$} & \multicolumn{2}{|l|}{ Adjusted $\mathrm{OR}^{*}$} \\
\hline & & & & $(95 \% \mathrm{Cl})$ & P-value & $(95 \% \mathrm{Cl})$ & P-value \\
\hline Reduced alcohol use among drinkers & 1,139 & & & & & & \\
\hline Yes & $88(7.7)$ & $22(25.0)$ & $66(75.0)$ & 1 (reference) & & 1 (reference) & \\
\hline No & $243(21.3)$ & $43(17.7)$ & $200(82.3)$ & $0.645(0.360-1.157)$ & 0.141 & $0.727(0.398-1.330)$ & 0.301 \\
\hline Unknown & $808(70.9)$ & & & & & & \\
\hline Reduction in frequency of alcohol consumption & 1,139 & & & & & & \\
\hline No change & $201(17.6)$ & $38(18.9)$ & $163(81.1)$ & 1 (reference) & & 1 (reference) & \\
\hline$<1 /$ wk & $24(2.1)$ & $2(8.3)$ & $22(91.7)$ & $0.390(0.088-1.730)$ & 0.215 & $0.421(0.093-1.895)$ & 0.260 \\
\hline $1-2 /$ wk & $14(1.2)$ & $2(14.3)$ & $12(85.7)$ & $0.715(0.154-3.328)$ & 0.669 & $0.569(0.119-2.713)$ & 0.479 \\
\hline$>3 / w k$ & $4(0.4)$ & $1(25.0)$ & $3(75.0)$ & $1.430(0.145-14.127)$ & 0.760 & $1.500(0.145-150494)$ & 0.734 \\
\hline Unknown ${ }^{\dagger}$ & $896(78.7)$ & & & & & & \\
\hline Increased body mass index & 1,062 & & & & & & \\
\hline Yes & 250 & $59(23.6)$ & $191(76.4)$ & 1 (reference) & & 1 (reference) & \\
\hline No & 812 & $101(12.4)$ & $711(87.6)$ & $2.175(1.519-3.113)$ & $<0.001$ & $2.010(1.388-2.911)$ & $<0.001$ \\
\hline$>0.5 \mathrm{~kg} / \mathrm{m}^{2}$ & $96(9.0)$ & $25(26.0)$ & $71(74.0)$ & 1 (reference) & & 1 (reference) & \\
\hline$\leq 0.5 \mathrm{~kg} / \mathrm{m}^{2}$ & $966(91.0)$ & $135(14.0)$ & $831(86.0)$ & 2.044 (1.420-2.942) & $<0.001$ & 2.189 (1.309-3.659) & 0.003 \\
\hline Increased physical activity & 965 & & & & & & \\
\hline Yes & 882 & $128(14.5)$ & $754(85.5)$ & 1 (reference) & & 1 (reference) & \\
\hline No & 83 & $21(25.3)$ & $62(74.7)$ & $1.995(1.175-3.387)$ & 0.011 & 2.377 (1.351-4.183) & 0.003 \\
\hline Reduced salt intake & 1,096 & & & & & & \\
\hline Yes & 408 & $52(12.7)$ & $356(87.3)$ & 1 (reference) & & 1 (reference) & \\
\hline No & 688 & $121(17.6)$ & 567 (82.4) & $1.461(1.029-2.075)$ & 0.034 & $1.324(0.914-1.917)$ & 0.138 \\
\hline
\end{tabular}

Values are presented as number or number (\%).

$\mathrm{OR}$, odds ratio; $\mathrm{Cl}$, confidence interval.

*Multivariate OR calculated by adjusting for age, sex, and comorbidity. ${ }^{+}$Persons with no classification.

Table 4. Blood pressure control trend by individual salt intake

\begin{tabular}{|c|c|c|c|c|c|}
\hline Variable & Total & Success & Failure & Odds ratio (95\% confidence interval) & P-value \\
\hline Self-reported level of salt intake & 1,109 & & & & \\
\hline Very high & $240(21.6)$ & $188(78.3)$ & $52(21.7)$ & 1 (reference) & \\
\hline Moderate & $684(61.7)$ & $594(86.8)$ & $90(13.2)$ & $1.826(1.250-2.666)$ & 0.002 \\
\hline Less & $185(16.7)$ & $153(82.7)$ & $32(17.3)$ & $1.322(0.811-2.157)$ & 0.263 \\
\hline Use of salt/soy sauce & 1,104 & & & & \\
\hline Always & $73(6.6)$ & $55(75.3)$ & $18(24.7)$ & 1 (reference) & \\
\hline Frequent & $176(15.9)$ & $140(79.5)$ & $36(20.5)$ & $1.273(0.667-2.428)$ & 0.464 \\
\hline Rarely & $419(38.0)$ & $341(81.4)$ & $78(18.6)$ & $1.431(0.796-2.572)$ & 0.231 \\
\hline Never & $436(39.5)$ & $395(90.6)$ & $41(9.4)$ & $3.153(1.693-5.872)$ & $<0.001$ \\
\hline Use of soy sauce when eating fried food & 1,104 & & & & \\
\hline Always & $96(8.7)$ & $71(74.0)$ & $25(26.0)$ & 1 (reference) & \\
\hline Sometimes & $547(49.5)$ & $453(82.8)$ & $94(17.2)$ & 1.697 (1.022-2.818) & 0.041 \\
\hline Never & $461(41.8)$ & $406(88.1)$ & 55 (11.9) & 2.599 (1.521-4.442) & $<0.001$ \\
\hline
\end{tabular}

Values are presented as number or number (\%).

long-term aerobic exercise are not completely understood, while a reduction in sympathetic activity and an improvement in endothelial function have been proposed as mechanisms affecting blood pressure. ${ }^{15)}$ In one randomized trial, patients with a recent myocardial infarction showed improved baroreceptor sensitivity and reduced muscle sympathetic nerve activity with exercise training. ${ }^{16)}$ Another study that compared muscle biopsies in patients with hypertension before and after an exercise program documented decreased levels of the vasoconstrictor thromboxane and increased levels of the vasodilator prostacyclin. ${ }^{17)}$ In our study, we used MET scores to assess physical ac- tivity and observed changes within 12 weeks of treatment. The adjusted OR for the answer "no" for increased physical activity (which included no change or a decreased MET score after 12 weeks) was 0.43 for successful blood pressure control (Table 3).

A variety of dietary modifications are known to be beneficial in the treatment of hypertension, including reduction of sodium intake; moderation of alcohol intake; weight loss in overweight or obese individuals; and a diet rich in fruits, vegetables, legumes, and low-fat dairy products, and also low in snacks, sweets, meat, and saturated fat. Individual dietary factors may also be helpful in lowering blood pressure. ${ }^{18)}$ 
In our study, we focused on the association between reduction in salt intake and blood pressure control by using self-reported survey questions. Aburto et al. ${ }^{19)}$ found that in non-acutely ill adults, reduced sodium intake reduced blood pressure and had no adverse effect on blood lipids, catecholamine levels, or renal function. Moderate quality evidence in children showed that a reduction in sodium intake reduced blood pressure. Lower sodium intake was also associated with a reduced risk of stroke and fatal coronary heart disease in adults. ${ }^{19)}$

One study estimated the daily salt intake among the US population to be 10.0 to $14.5 \mathrm{~g}$, with about one-third occurring naturally in food, one-third added during food processing, and one-third added by the consumer. Males consume more sodium than females and the intake of both sexes decline with age. ${ }^{20)}$ Discretionary sodium intake among Koreans was estimated to be $45 \%$ to $85 \%$, which tends to be higher than in Western countries. A study by Kim et al. ${ }^{10)}$ studied the relationship between 24-hour urinary sodium excretion and salt usage in order to develop valid questionnaires to estimate dietary salt intake. The study showed the median 24-hour urinary sodium excretion among the study subjects ranged from 129 to $216 \mathrm{mmol}$, depending on the age and sex, ${ }^{10)}$ while approximately $90 \%$ of the world's population has a mean usual sodium intake within a range of approximately 115 to $215 \mathrm{mmol}$ ( \pm 2 standard deviation) ${ }^{21)}$ By evaluating the correlation coefficient, Kim et al. ${ }^{10)}$ derived 3 questions that may be useful in estimating the sodium intake of the Korean adult population. We used those 3 questions in our study to assess the habit of salt intake and to observe changes in salt intake 12 weeks after initiating treatment for hypertension (Table 4). For each question, participants with less salt intake tended to be more successful in blood pressure control. The correlation between less salt intake and blood pressure control was statistically significant especially for question 3 , "Usage of soy sauce when eating fried food." In Table 4, we used a 12-point scale (example, 12, 8, 4 , and 0 ) for each question. In order to maintain continuity, in Table 5 , we converted the answers into 3 categories (increased, same, and decreased) and evaluated the association with blood pressure control. As a result, for all 3 questions, decreased salt intake was positively associated with successful blood pressure control; however, statistical signifi- cance was only maintained in question 3.

In phase 1 of the Trials of Hypertension Prevention, during an 18-month follow-up period, the weight reduction program was shown to be an effective non-pharmacologic intervention for reducing blood pressure in overweight adults with high to normal blood pressure. ${ }^{22)}$ In our study, participants with the same or decreased BMI in the 12-week period showed better blood pressure control. We analyzed for both changes in the absolute BMI and set a standard of $>0.5 \mathrm{~kg} / \mathrm{m}^{2}$ as a significant increase in BMI. The result from both analyses showed statistical significance in which increased BMI was inversely related to successful blood pressure control.

As the locations of clinics which our data were collected are large metropolitan area, there for there can be geographical bias. In addition, the follow-up survey period was 12 weeks, and only blood pressure control and other lifestyle changes were observed in this short period of time. Therefore, the associations cannot be established with certainty about long-term effects. Since the survey asked the patients to answer questions about their behaviors during the past several weeks at each clinic visit, there is also a possibility of recall bias. Other limitations include the relative lack of quantitative analysis on lifestyle changes, such as habit of salt intake, smoking status, and alcohol consumption. Important strengths include the large number of participants that were included in the study. The blood pressure measurements were conducted at clinics that provided reliable data, and survey questions were filled out at each clinic visit, for convenience of the patients, and for follow-up study.

Conclusions from the eighth Joint National Committee guidelines, which is based on evidence from randomized controlled trials, suggest that a health eating, weight management, and appropriate physical activity are essential for the management of high blood pressure in adults, since these lifestyle managements have the potential to improve blood pressure control and even reduce the need for medication. ${ }^{23)}$ Our findings indicate that to achieve better rates of blood pressure control, the clinician should advise lifestyle modifications such as adequate physical activity and low salt intake, in addition to prescribing medication and monitoring the patient for hypertension control.

Table 5. Blood pressure control trend by individual salt intake (scale conversion)

\begin{tabular}{|c|c|c|c|c|c|}
\hline Variable & Total & Success & Failure & Adjusted odds ratio (95\% confidence interval) & P-value \\
\hline Self-reported level of salt intake & 1,109 & & & & \\
\hline Increased & $37(3.3)$ & $30(81.8)$ & $7(18.9)$ & 1 (reference) & \\
\hline Same & $845(76.2)$ & $704(83.3)$ & $141(16.7)$ & $1.176(0.494-2.800)$ & 0.714 \\
\hline Decreased & $227(20.5)$ & 201 (88.5) & $26(11.5)$ & $1.583(0.616-4.067)$ & 0.340 \\
\hline Use of salt/soy sauce & 1,101 & & & & \\
\hline Increased & $75(6.8)$ & $59(78.7)$ & $16(21.3)$ & 1 (reference) & \\
\hline Same & $713(64.8)$ & $594(83.3)$ & $119(16.7)$ & $1.430(0.765-2.670)$ & 0.262 \\
\hline Decreased & $313(28.4)$ & $275(87.9)$ & $38(12.1)$ & $1.543(0.775-3.074)$ & 0.217 \\
\hline Use of soy sauce when eating fried food & 1,101 & & & & \\
\hline Increased & $34(3.1)$ & $22(64.7)$ & $12(35.3)$ & 1 (reference) & \\
\hline Same & $850(77.2)$ & $716(84.2)$ & $134(15.8)$ & 3.187 (1.483-6.848) & 0.003 \\
\hline Decreased & $217(19.7)$ & $189(87.1)$ & $28(12.9)$ & 3.687 (1.581-8.600) & 0.003 \\
\hline
\end{tabular}

Values are presented as number of number (\%). 


\section{CONFLICT OF INTEREST}

No potential conflict of interest relevant to this article was reported.

\section{REFERENCES}

1. World Health Organization. Global health risks: mortality and burden of disease attributable to selected major risks. Paris: World Health Organization; 2009.

2. Kim CY, Lee KS, Khang YH, Yim J, Choi YJ, Lee HK, et al. Health behaviors related to hypertension in rural population of Korea. Korean J Prev Med 2000;33:56-68.

3. Collins R, Peto R, MacMahon S, Hebert P, Fiebach NH, Eberlein KA, et al. Blood pressure, stroke, and coronary heart disease: part 2, shortterm reductions in blood pressure: overview of randomised drug trials in their epidemiological context. Lancet 1990;335:827-38.

4. Trilling JS, Froom J. The urgent need to improve hypertension care. Arch Fam Med 2000;9:794-801.

5. Bruno RM, Pucci G, Rosticci M, Guarino L, Guglielmo C, Agabiti Rosei $\mathrm{C}$, et al. Association between lifestyle and systemic arterial hypertension in young adults: a national, survey-based, cross-sectional study. High Blood Press Cardiovasc Prev 2016;23:31-40.

6. Lee SY. Health care policy and its challenges. Sejong: Korea Institute for Health and Social Affairs; 2015.

7. Wee LE, Wong J, Chin RT, Lin ZY, Goh DE, Vijakumar K, et al. Hypertension management and lifestyle changes following screening for hypertension in an Asian low socioeconomic status community: a prospective study. Ann Acad Med Singapore 2013;42:451-65.

8. Lee JA, Kim WS, Bae MJ, Kim YS, Oh HJ, Lee SY, et al. The effectiveness of short term mobile phone text reminders in improving compliance among hypertensive patients. Korean J Health Promot 2014;14:1-8.

9. International Physical Activity Questionnaire Research Committee. Guidelines for data processing and analysis of the International Physical Activity Questionnaire (IPAQ): short and long forms. [place unknown]: International Physical Activity Questionnaire Research Committee; 2005.

10. Kim HJ, Paik HY, Lee SY, Shim JE, Kim YS. Salt usage behaviors are related to urinary sodium excretion in normotensive Korean adults. Asia Pac J Clin Nutr 2007;16:122-8.

11. Cheong W, Yim J, Oh DK, Im JS, Ko KP, Kim YM. Effects of chronic disease management based on clinics for blood pressure or glycemic control in patients with hypertension or type 2 diabetes mellitus. J Ag- ric Med Community Health 2013;38:108-15.

12. Hajjar I, Kotchen TA. Trends in prevalence, awareness, treatment, and control of hypertension in the United States, 1988-2000. JAMA 2003;290:199-206.

13. Turner BJ, Hollenbeak CS, Weiner M, Ten Have T, Tang SS. Effect of unrelated comorbid conditions on hypertension management. Ann Intern Med 2008;148:578-86.

14. Bramlage P, Bohm M, Volpe M, Khan BV, Paar WD, Tebbe U, et al. A global perspective on blood pressure treatment and control in a referred cohort of hypertensive patients. J Clin Hypertens (Greenwich) 2010;12:666-77.

15. Goto C, Higashi Y, Kimura M, Noma K, Hara K, Nakagawa K, et al. Effect of different intensities of exercise on endothelium-dependent vasodilation in humans: role of endothelium-dependent nitric oxide and oxidative stress. Circulation 2003;108:530-5.

16. Martinez DG, Nicolau JC, Lage RL, Toschi-Dias E, de Matos LD, Alves $\mathrm{MJ}$, et al. Effects of long-term exercise training on autonomic control in myocardial infarction patients. Hypertension 2011;58:1049-56.

17. Hansen AH, Nyberg M, Bangsbo J, Saltin B, Hellsten Y. Exercise training alters the balance between vasoactive compounds in skeletal muscle of individuals with essential hypertension. Hypertension 2011;58:943-9.

18. Chobanian AV, Bakris GL, Black HR, Cushman WC, Green LA, Izzo JL Jr, et al. The seventh report of the Joint National Committee on Prevention, Detection, Evaluation, and Treatment of High Blood Pressure: the JNC 7 report. JAMA 2003;289:2560-72.

19. Aburto NJ, Ziolkovska A, Hooper L, Elliott P, Cappuccio FP, Meerpohl JJ. Effect of lower sodium intake on health: systematic review and meta-analyses. BMJ 2013;346:f1326.

20. Fregly MJ. Estimates of sodium and potassium intake. Ann Intern Med 1983;98(5 Pt 2):792-9.

21. Graudal N, Jurgens G, Baslund B, Alderman MH. Compared with usual sodium intake, low- and excessive-sodium diets are associated with increased mortality: a meta-analysis. Am J Hypertens 2014;27:1129-37.

22. Stevens VJ, Corrigan SA, Obarzanek E, Bernauer E, Cook NR, Hebert P, et al. Weight loss intervention in phase 1 of the Trials of Hypertension Prevention. The TOHP Collaborative Research Group. Arch Intern Med 1993;153:849-58.

23. James PA, Oparil S, Carter BL, Cushman WC, Dennison-Himmelfarb C, Handler J, et al. 2014 evidence-based guideline for the management of high blood pressure in adults: report from the panel members appointed to the Eighth Joint National Committee (JNC 8). JAMA 2014;311:507-20. 